\title{
FENOLOGIA DA FRUTIFICAÇÃO E ESTRATÉGIAS DE DISPERSÃO DE ÁRVORES E ARBUSTOS EM UM FRAGMENTO URBANO NO SUL DE SANTA CATARINA, BRASIL
}

\section{FRUITING PHENOLOGY AND DISPERSAL STRATEGIES OF TREES AND SHRUBS IN AN URBAN FOREST REMNANT IN THE SOUTH OF SANTA CATARINA, BRAZIL}

\author{
Alexandra Rocha Vinholes ${ }^{1}$ \\ Lilian Sombrio Delfino ${ }^{2}$ \\ Alexandre Bianco ${ }^{3}$ \\ Birgit Harter-Marques ${ }^{41}$
}

\begin{abstract}
RESUMO
O estudo foi realizado em um fragmento urbano de Floresta Ombrófila Densa das Terras Baixas, no município de São João do Sul, sul de Santa Catarina, com o objetivo de identificar a época de frutificação das espécies vegetais arbustivo-arbóreas e suas estratégias de dispersão. Foram marcados um a três indivíduos de cada espécie vegetal que estava frutificando, classificado sua estratégia de dispersão e, quinzenalmente, foi realizado acompanhamento do estágio de maturação dos frutos, no período de novembro/2009 a setembro/2010. Foram encontradas 18 espécies vegetais com frutos pertencentes a dez famílias botânicas. Melastomataceae, Myrtaceae e Rubiaceae foram às famílias mais representativas com quatro espécies cada uma. Ocorreu disponibilidade de frutos durante todo o ano. A zoocoria foi a estratégia de dispersão encontrada em 17 espécies e a autocoria em apenas uma espécie. Os resultados evidenciam a realização de mais estudos sobre a fenologia e estratégias de dispersão de diásporos das espécies vegetais em fragmentos urbanos com inclusão de diferentes hábitos, visto que foi encontrado um número baixo de espécies arbóreas e arbustivas com frutos.
\end{abstract}

PALAVRAS-CHAVE: Zoocoria, espécies arbóreas, fragmento florestal, Mata Atlântica.

\section{ABSTRACT}

The study was conducted in an urban fragment of Submontane Dense Ombrophilous Forest, in São João do Sul, southern Santa Catarina, in order to identify the fruiting period of shrub and woody plant species, and dispersion strategies. One to three individuals of each fruiting plant species was marked, their dispersal strategy was classified, and fortnightly the ripening stage of fruits was monitorated, from November 2009 to September 2010. We have found 18 plant species with fruits belonging to ten

\footnotetext{
1 Laboratório de Interação Animal-Planta, Universidade do Extremo Sul Catarinense (UNESC), Criciúma, Santa Catarina.

${ }^{2}$ Mestre em Ciências Ambientais pelo Programa de Pós-Graduação em Ciências Ambientais (PPGCA), Universidade do Extremo Sul Catarinense (UNESC), Criciúma, Santa Catarina.

${ }^{3}$ Biólogo, Curso de Ciências Biológicas, UNESC.

${ }^{4}$ Docente do Programa de Pós-Graduação em Ciências Ambientais (PPGCA), Universidade do Extremo Sul Catarinense (UNESC), Av. Universitária, Bairro Universitário, CEP 88806-000, Criciúma, Santa Catarina. E-mail: bhm@unesc.net
} 
plant families. Melastomataceae, Rubiaceae and Mytaceae were the most representative families with four species each. Fruit availability occurred throughout the year. The zoochory dispersion strategy was found in 17 species and autocory in only one species. The results show that more studies on fruiting phenology and dispersal strategies in urban fragments which include different habits have to carry out, because a low number of tree and shrub species with fruits was found.

KEYWORDS: Zoochory, tree species, forest remnant, Atlantic Forest.

\section{INTRODUÇÃO}

Estudos fenológicos em ecossistemas florestais têm sido realizados em todo o mundo basicamente em dois níveis de abordagem: populações (espécies) ou comunidades. Estes estudos têm caráter qualitativo, onde são levantadas as épocas do ano em que ocorrem as fenofases, ou quantitativo, onde as fenofases são medidas em termos de intensidade do evento (FOURNIER, 1974).

Andreis et al. (2005) definem a fenologia como uma ciência que identifica os fenômenos vegetais de floração, frutificação, queda e brotamento foliar. Tais fenômenos contribuem para o entendimento da reprodução das plantas, da organização temporal dos recursos dentro das comunidades, das interações planta-animal e da evolução da história de vida dos animais que dependem de plantas para alimentação, como herbívoros, polinizadores e dispersores.

Dentre os agentes que influenciam os ritmos fenológicos, destacam-se os fatores bióticos e abióticos. Os fatores bióticos incluem adaptações morfológicas e fisiológicas, além da interação com polinizadores e dispersores (van SCHAIK et al., 1993; FENNER, 1998). Entre os fatores abióticos, a precipitação, a temperatura e o comprimento do dia são considerados os mais importantes, atuando como reguladores da época, intensidade, duração e periodicidade dos eventos fenológicos (MORELLATO et al., 2000).

De acordo com Morellato e Leitão-Filho (1990, 1992, 1996), Morellato et al. (1989, 1990) e van Schaik et al. (1993), vegetações com climas mais sazonais apresentam maior periodicidade na produção de flores, folhas e frutos, onde a alternância de estações seca e úmida é apontada como o principal fator envolvido no desencadeamento das fenofases. Por outro lado, Longman e Jenik (1987) afirmam que picos e depressões nas curvas fenológicas de floração, frutificação e brotamento não 
ocorrem apenas em climas com estação seca definida, mas também em florestas úmidas onde as condições climáticas variam de forma leve ou irregular.

Apesar de sua grande importância, estudos de fenologia em ambientes florestais em nível de comunidade ainda são escassos. No Brasil destacam-se os trabalhos de Araújo (1970), Alencar et al. (1979), Pires (1991) e Freitas (1996), na Amazônia brasileiras; os trabalhos de Vasconcellos (2006) e Figueiredo (2008), no Nordeste. No Estado de São Paulo, os trabalhos de Morellato et al. (1989, 1990), Morellato e LeitãoFilho (1990, 1992, 1996), Morellato (1991, 1995) e Talora e Morellato (2000), realizados em matas semidecíduas no interior do estado. No estado do Rio de Janeiro destacam-se os trabalhos de Figueiredo (2007) e Pereira et al. (2008).

No sul do país, no estado do Rio Grande do Sul, foram realizados trabalhos por Andreis et al. (2005), Marchioreto et al. (2007) e Athayde et al. (2009). Em Santa Catarina, pode-se destacar os trabalhos de Mantovani et al. (2003), Wessler (2008). E no estado do Paraná destacam-se Carmo e Morelatto (2000), Mikich e Silva (2001), Marques e Oliveira (2004) e Palioto et al. (2007).

Assim como os padrões fenológicos, a dispersão das sementes e a avaliação da disponibilidade de frutos são aspectos praticamente desconhecidos nos estudos (REYS et al., 2005). Segundo van der Pijl (1982), a dispersão de sementes por animais frugívoros constitui um processo no qual as plantas têm suas sementes dispersas e os dispersores, em troca, recebem um retorno nutricional na forma de um pericarpo carnoso comestível.

A dispersão é um dos processos mais importantes da regeneração natural de florestas tropicais, sendo também importante para a recuperação de áreas degradadas por atividades antrópicas (GRIFFITH et al., 1996). De acordo com Figlioolia (1993), o processo de dispersão é muito complexo, envolvendo relações específicas entre plantas e agentes dispersores.

Plantas com frutos zoocóricos apresentam uma série de características, como a presença de uma porção comestível envolvendo a semente e cores atrativas, que estimulam e facilitam o seu consumo por animais e, consequentemente, a dispersão de suas sementes (van der PIJL 1982; HOWE; SMALLWOOD, 1982).

As plantas que se encaixam na síndrome ornitocórica frequentemente possuem frutos com uma porção carnosa, cores contrastantes, odor leve ou ausente e são bem 
expostos na planta (PIZO, 1996). Os fatores que governam a escolha dos frutos e a dispersão por aves são muito variáveis e podem incluir: a influência da cor, a acessibilidade aos frutos, a fenologia da frutificação, a competição por dispersores, a eficiência do dispersor e o conteúdo nutritivo do fruto (GONDIM, 2001).

Segundo Roth (1987), espécies de dispersão zoocóricas com frutos ou sementes pesadas e numerosas predominam nos estratos mais baixos da floresta, nos quais a vida animal seria mais intensa. Síndromes autocóricas, anemocóricas e zoocóricas com diásporos tipo drupa ou noz, com uma ou poucas sementes, predominam nos estratos superiores de florestas tropicais.

Plantas dispersas pelo vento seriam mais comuns em florestas secas, sob menor precipitação anual e nos estratos superiores, devido a melhores condições de exposição dos diásporos à ação do vento (MORELLATO, 1991). De acordo com a mesma autora, a autocoria está presente em espécies pioneiras, já que estas plantas não suportam muita competição interespecífica. Seu mecanismo de dispersão a curta distância teria vantagem de formar colônias ao redor da planta mãe, permitindo ocupar rapidamente um determinado espaço.

Dentre os agentes dispersores vertebrados, as aves desempenham um papel importante, não apenas pela sua abundância como também devido à frequência com que se alimentam de frutos (PIZO, 1996).

Considerando a forte pressão antrópica que a Mata Atlântica vem sofrendo ao longo de muitos anos, torna-se indispensável o incremento de estudos que contribuam no entendimento dos processos de reprodução e regeneração das plantas e subsidiem ações de recuperação das áreas degradadas. Camacho e Orozco (1998) ressaltam ainda que, ampliando a compreensão dos padrões fenológicos das espécies arbóreas nos ecossistemas naturais, bem como de suas interações com a fauna, é possível gerar conhecimento para programas de conservação de recursos genéticos. Sendo assim, este estudo teve como objetivo acompanhar o período de frutificação das espécies vegetais arbustivo-arbóreas no período de um ano, bem como classificar suas estratégias de dispersão. 


\section{METODOLOGIA}

\section{1 Área de estudo}

O estudo foi realizado em um fragmento urbano, de propriedade privada, de Floresta Ombrófila Densa das Terras Baixas (29 13'S15”S e 49 47’52”O), localizada no município de São João do Sul, região sul de Santa Catarina, Brasil (Figuras 1 e 2). O fragmento possui área de aproximadamente sete hectares, dos quais somente três foram utilizados como unidade amostral. No fragmento estudado ocorreu corte seletivo até 45 anos atrás. Entretanto, desde então, não sofreu mais nenhum distúrbio por ação antrópica. Desta forma, foi caracterizado como um remanescente de Floresta Ombrófila Densa das Terras Baixas em estágio médio de regeneração natural.

As florestas nativas do município foram extremamente fragmentadas, devido, principalmente, às atividades de agricultura, retirada de lenha para estufas de fumo e urbanização, que vem acarretando no crescente isolamento dos remanescentes. Dessa forma, grande parte da riqueza biológica local foi perdida ou encontra-se seriamente ameaçada.

Figura 1. Localização do estado de Santa Catarina e do município de São João do Sul, no sul do Estado de Santa Catarina.

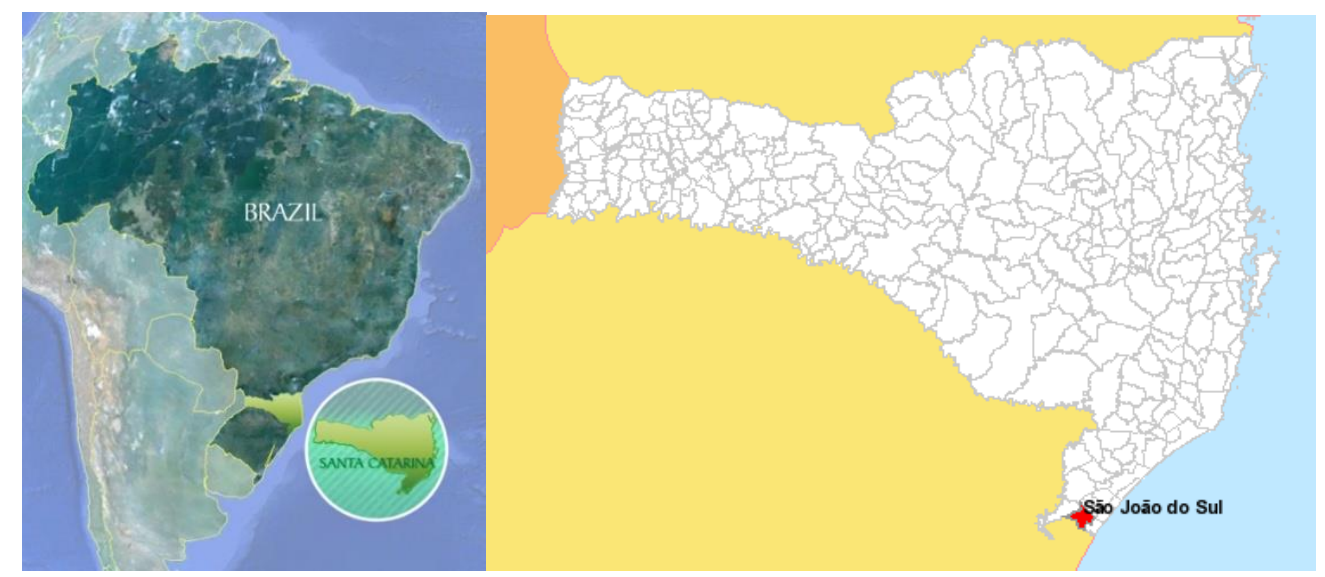

Fonte: Universidade do Estado de Santa Catarina; Mapa Interativo de Santa Catarina.

Figura 2. Localização da área de estudo em São João do Sul, Santa Catarina. 


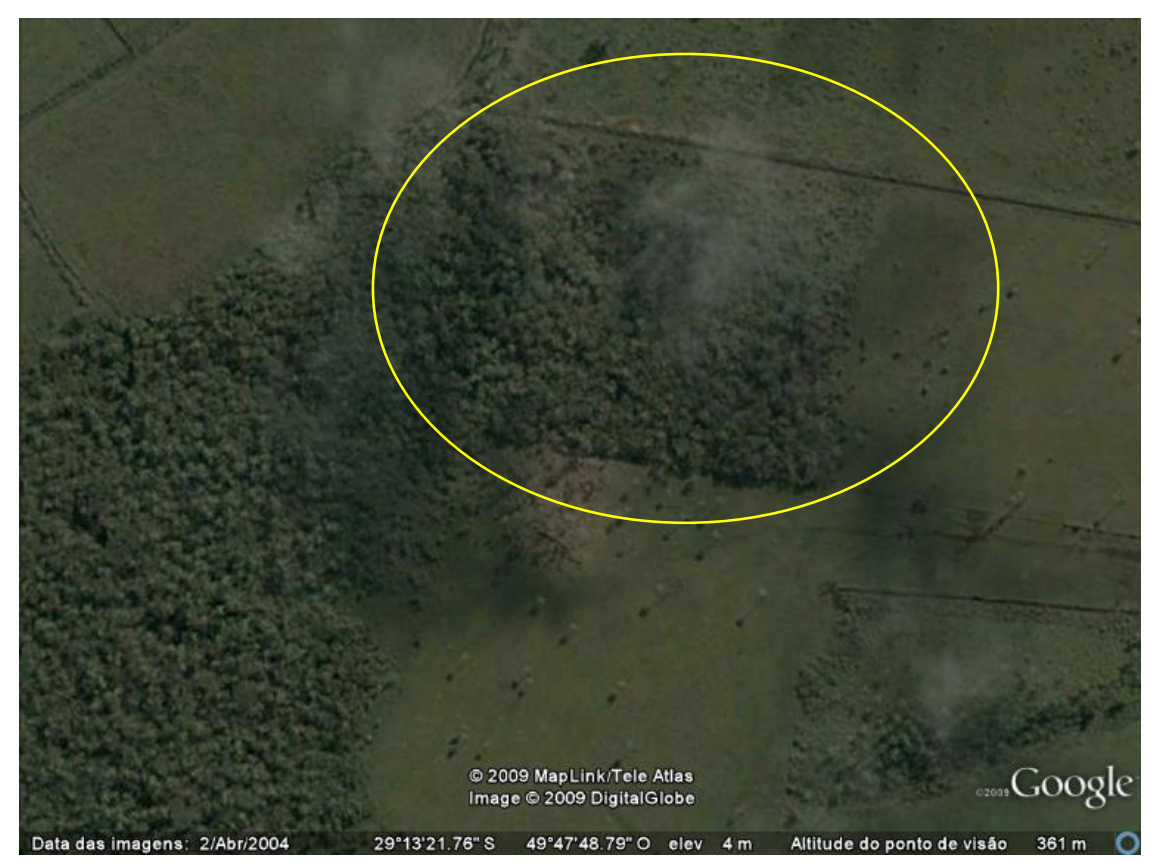

Fonte: Google Earth, modificado (2011).

O município de São João do Sul pertence à Associação dos Municípios do Extremo Sul Catarinense (AMESC, 2010), possui uma área territorial de $182.699 \mathrm{~km}^{2}$, contando em 2008 com uma população de 7.143 habitantes. O clima do município está classificado como Cfa, segundo Köppen, ou seja, clima subtropical constantemente úmido, sem estação seca, com verão quente (temperatura média do mês mais quente > $22^{\circ} \mathrm{C}$ ). Segundo Braga e Ghellre (1999), o clima é mesotérmico brando com temperatura do mês mais frio entre $0^{\circ} \mathrm{C}$ e $5^{\circ} \mathrm{C}$ e temperatura média anual de $17^{\circ} \mathrm{C}$ a $19,3^{\circ} \mathrm{C}$ e a umidade relativa média do ar é de $82 \%$ (PMSJS, 2010).

O solo da região é classificado como Neossolos e Organossolos (EPAGRI/CIRAM, 2001), e está sobre abrangência da zona agroecológica B2 (SANTA CATARINA, 2002).

\subsection{Fenologia da frutificação}

Para o acompanhamento da fenologia da frutificação das espécies arbustivoarbóreas foram percorridos, quinzenalmente, dois transectos de $200 \mathrm{~m}$ de comprimento cada, estabelecidos na borda e no interior do fragmento, entre os meses de novembro de 2009 e setembro de 2010 (Figura 3). Para tal, foram marcados de um a três indivíduos de cada espécie vegetal encontrada com frutos. A fenofase de frutificação foi acompanhada desde a formação dos frutos verdes até a ausência de frutos nos 
indivíduos, porém, para análise de dados foi considerada apenas a época em que surgiram os primeiros frutos maduros.

Figura 3. Localização dos transectos no fragmento estudado em São João do Sul, Santa Catarina. Cor amarela - transecto borda/Cor azul - transecto interior.

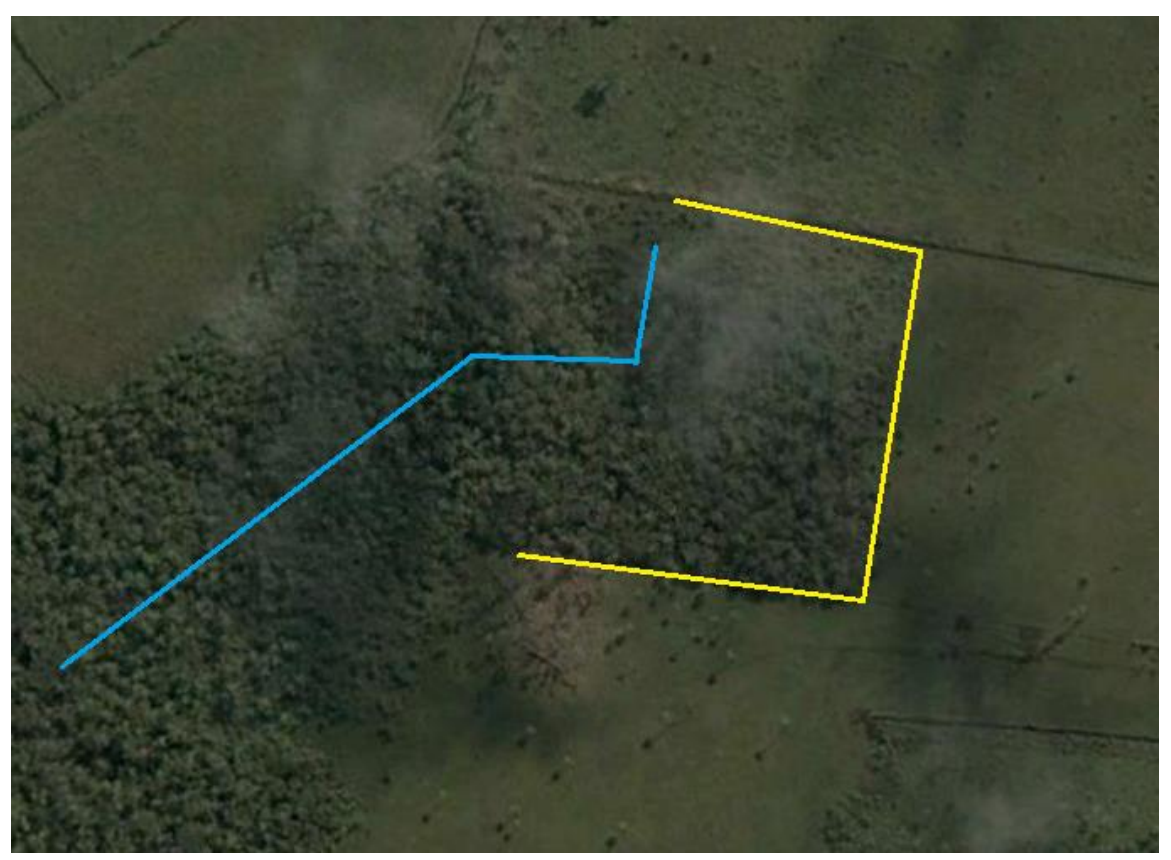

Fonte: Google Earth, modificado (2011).

Os eventos fenológicos foram registrados, utilizando-se a seguinte escala para a presença/ausência de frutos e o estágio de maturação dos mesmos (MIKICH; SILVA, 2001):

0 - ausência de frutos;

$1-100 \%$ de frutos imaturos;

$2-1 \%$ a $25 \%$ dos frutos maduros;

$3-26 \%$ a $50 \%$ dos frutos maduros;

$4-51 \%$ a $75 \%$ dos frutos maduros;

$5-76 \%$ a $100 \%$ dos frutos maduros.

De cada espécie marcada foram coletados ramos férteis para posterior identificação, realizada por especialistas do Herbário Pe. Dr. Raulino Reitz (CRI) da 
Universidade do Extremo Sul Catarinense (UNESC), sendo as famílias reunidas segundo as delimitações de APG III (2009).

\subsection{Estratégias de dispersão de diásporos}

As estratégias de dispersão de diásporos foram identificadas em campo e classificadas, segundo van der Pijl (1982), em: 1) anemocóricas (quando os diásporos apresentam-se alados, plumosos ou em forma de balão ou poeira); 2) zoocóricas (quando apresentam atrativos e/ou formas alimentares em seus diásporos e aqueles com estruturas adesivas - ganchos, cerdas, espinhos); e 3) autocóricas (aquelas que não se encaixam nas duas categorias anteriores, incluindo as espécies barocóricas e aquelas com dispersão explosiva).

\section{RESULTADOS E DISCUSSÃO}

\subsection{Fenologia de frutificação}

Foram encontradas 18 espécies em frutificação pertencentes a dez famílias botânicas durante o período da pesquisa, das quais 11 espécies foram arbóreas e sete arbustivas (Tabela 1).

No estudo realizado por Wessler (2008), na área de entorno do aterro sanitário da empresa SANTEC Resíduos, com 4 ha, no município de Içara, Santa Catarina, foram encontradas 52 espécies arbóreas e nove arbustivas, ao longo de 12 meses. Em comparação ao presente estudo, pode-se afirmar que o fragmento estudado apresenta um baixo número de espécies arbóreas. Este baixo número de espécies vegetais encontradas na área pesquisada pode ser atribuído ao fato que os dois fragmentos pertencem a formações florestais diferentes (Wessler, 2008 - Floresta Ombrófila Densa Submontana; remanescente estudado - Floresta Ombrófila Densa das Terras Baixas), sendo que as mesmas apresentam consideráveis diferenças de solos o que influencia diretamente na composição da vegetação.

Myrtaceae e Rubiaceae foram as famílias mais representativas, apresentando quatro espécies cada. A família Melastomataceae apresentou três e as famílias Arecaceae, Aquifoliaceae, Fabaceae, Malpighiaceae, Meliaceae, Myrsinaceae e Rutaceae apresentaram apenas uma espécie. 
Tabela 1: Espécies em frutificação acompanhadas durante 11 meses no fragmento estudado em São João do Sul, SC, indicando seu período de frutificação ( 1 = frutos imaturos, $2=1$ a $25 \%$ de frutos maduros, $3=26$ a $50 \%$ de frutos maduros, $4=$ entre 51 e $75 \%$ de frutos maduros, $5=76$ a $100 \%$ de frutos maduros), estratégia de dispersão $($ Zoo = zoocórica, Ane = anemocórica, Aut = autocórica $)$, seu hábito de crescimento $($ Arbo $=$ Arbóreo, Arbu = Arbusto $)$.

\begin{tabular}{|c|c|c|c|c|c|c|c|c|c|c|c|c|c|}
\hline \multirow{2}{*}{ Família/Espécie } & \multicolumn{11}{|c|}{ Período de frutificação } & \multirow{2}{*}{ Disp } & \multirow{2}{*}{ Hábito } \\
\hline & nov & dez & jan & fev & mar & abr & maio & jun & jul & ago & set & & \\
\hline \multicolumn{14}{|l|}{ AQUIFOLIACEAE } \\
\hline Ilex pseudobuxus Reissek & & 1 & 1 & 2 & 4 & 4 & 4 & 4 & 4 & & & Zoo & Arbo \\
\hline \multicolumn{14}{|l|}{ ARECACEAE } \\
\hline $\begin{array}{l}\text { Syagrus romanzoffiana } \\
\text { (Cham.) Glassman } \\
\text { FABACEAE }\end{array}$ & 2 & & & & & & & & & & & Zoo & Arbo \\
\hline Inga sessilis (Vell.) Mart. & & & & & & 2 & & & & & & Zoo & Arbo \\
\hline \multicolumn{14}{|l|}{ MALPIGHIACEAE } \\
\hline $\begin{array}{l}\text { Byrsonima ligustrifolia A. } \\
\text { Juss. }\end{array}$ & & 1 & 1 & 4 & 5 & & & & & & & Zoo & Arbo \\
\hline \multicolumn{14}{|l|}{ MELASTOMATACEAE } \\
\hline Miconia cinerascens Miq. & & 1 & 1 & 1 & 2 & 3 & 3 & 3 & 3 & & & Zoo & Arbu \\
\hline $\begin{array}{l}\text { Miconia ligustroides (DC.) } \\
\text { Naudin }\end{array}$ & & 1 & 3 & 5 & 5 & & & & & & & Zoo & Arbo \\
\hline Ossaea brachystachia Naudin & & 2 & 2 & 3 & 4 & 5 & & & & & & Zoo & Arbu \\
\hline \multicolumn{14}{|l|}{ MELIACEAE } \\
\hline Guarea macrophylla Vahl & 2 & & 2 & 2 & 1 & 2 & & 1 & 1 & & & Zoo & Arbu \\
\hline \multicolumn{14}{|l|}{ MYRSINACEAE } \\
\hline $\begin{array}{l}\text { Myrsine lorentziana }(\mathrm{Mez}) \\
\text { Arechav. }\end{array}$ & 4 & & & & & & 1 & 1 & 2 & 1 & 2 & Zoo & Arbo \\
\hline
\end{tabular}

\section{MYRTACEAE}

Marlierea eugeniopsoides $\underline{\text { (D. }}$

Legrand \& Kausel) D.

Legrand

Myrcia multiflora (Lam.) DC.

Myrcia palustris DC.

Zoo Arbu

Myrcia cf. pulchra (O.Berg)

Kiaersk.

\section{RUBIACEAE}

Faramea montevidensis

(Cham. \& Schltdl.) DC.

Psychotria sp.

Psychotria laciniata Vell.

Posoqueria latifolia (Rudge)

\begin{tabular}{|c|c|c|c|c|c|c|c|c|c|c|c|c|}
\hline & & & 1 & 1 & 1 & 3 & 3 & 4 & & & Zoo & Arbo \\
\hline & & & & 1 & 2 & & 3 & 4 & & & Zoo & Arbu \\
\hline 4 & 4 & 3 & 1 & 1 & 1 & & & & & & Zoo & Arbu \\
\hline & 4 & 3 & 4 & 4 & 4 & 4 & 3 & 2 & 3 & 4 & Zoo & Arbo \\
\hline
\end{tabular}




\begin{tabular}{|c|c|c|c|c|c|c|c|c|c|c|c|c|c|}
\hline \multirow{2}{*}{ Família/Espécie } & \multicolumn{11}{|c|}{ Período de frutificação } & \multirow{2}{*}{ Disp } & \multirow{2}{*}{ Hábito } \\
\hline & nov & dez & jan & fev & mar & abr & maio & jun & jul & ago & set & & \\
\hline \multicolumn{14}{|l|}{ RUTACEAE } \\
\hline Esenbeckia grandiflora Mart. & & 3 & 4 & 4 & 4 & 3 & 4 & 4 & 4 & 3 & 3 & Aut & Arbo \\
\hline
\end{tabular}

A família Melastomataceae ficou entre as três famílias mais ricas em espécies no estudo. No Brasil é a sexta maior família de Angiospermas com 68 gêneros e mais de 1.500 espécies, que se distribuem desde a Amazônia até o Rio Grande do Sul, estando presente em praticamente todas as formações vegetacionais com um número variável de espécies. As espécies desta família apresentam grande diversidade de hábitos, desde arbóreo até arbustivo e, mais rarament,e trepadeiras e epífitas, que permitem a ocupação de ambientes distintos e diversificados (ROMERO; MARTINS, 2002).

Myrtaceae encontra-se dentre as famílias de maior riqueza específica nas mais diversas formações vegetais brasileiras. Tem se destacado em numerosos levantamentos florísticos e fitossociológicos que incluem indivíduos arbustivos e arbóreos (ROMAGNOLO, 2009). Espécies de Myrtaceae são as mais representativas em muitos estudos realizados na região Sul do Brasil (MARTINS, 2005; NEGRELLE, 2006; SILVA, 2006; COLONETTI, 2011), corroborando os resultados deste estudo, visto que esta família esteve entre as mais ricas.

As espécies de Myrtaceae podem ser consideradas de grande importância ecológica, uma vez que apresentam características apícolas e produzem frutos comestíveis, muito apreciados pela fauna silvestre, sendo consumidos principalmente por aves, roedores, macacos, morcegos e peixes (MABBERLEY, 1997; BARROSO et al., 1999). Devido a estas características, as espécies desta família têm sido frequentemente indicadas para a revegetação de áreas perturbadas (LORENZI, 1992, 1998; POTT; POTT, 1994; BACKES; IRGANG, 2002).

A terceira família que se destacou como mais representativa foi Rubiaceae, que engloba cerca de 637 gêneros e aproximadamente 10.700 espécies (ROBBRECHT, 1988), sendo o gênero Psychotria o maior dentro da família (MABBERLEY, 1997). As espécies de Psychotria constituem fontes de néctar e de frutos para animais, fazendo parte dos recursos utilizados pela fauna de diversas comunidades de Florestas Semidecíduas (MORELLATO, 1992; GRANDISOLI, 1997), de Floresta Subtropical Montana (PACHECO; GRAU, 1997) e de Floresta Obrófila Densa (LIMA, 1988). 
O fragmento estudado disponibilizou frutos maduros durante todo o período da pesquisa (Figura 4). Os meses de maior pico de frutificação foram janeiro e março, com 13 espécies apresentando frutos maduros e o menor número de espécies frutificando ocorreu nos meses de agosto e setembro, com três espécies com frutos maduros.

Figura 4. Número de espécies com frutos maduros, disponíveis à fauna, no fragmento florestal estudado no município de São João do Sul, SC.

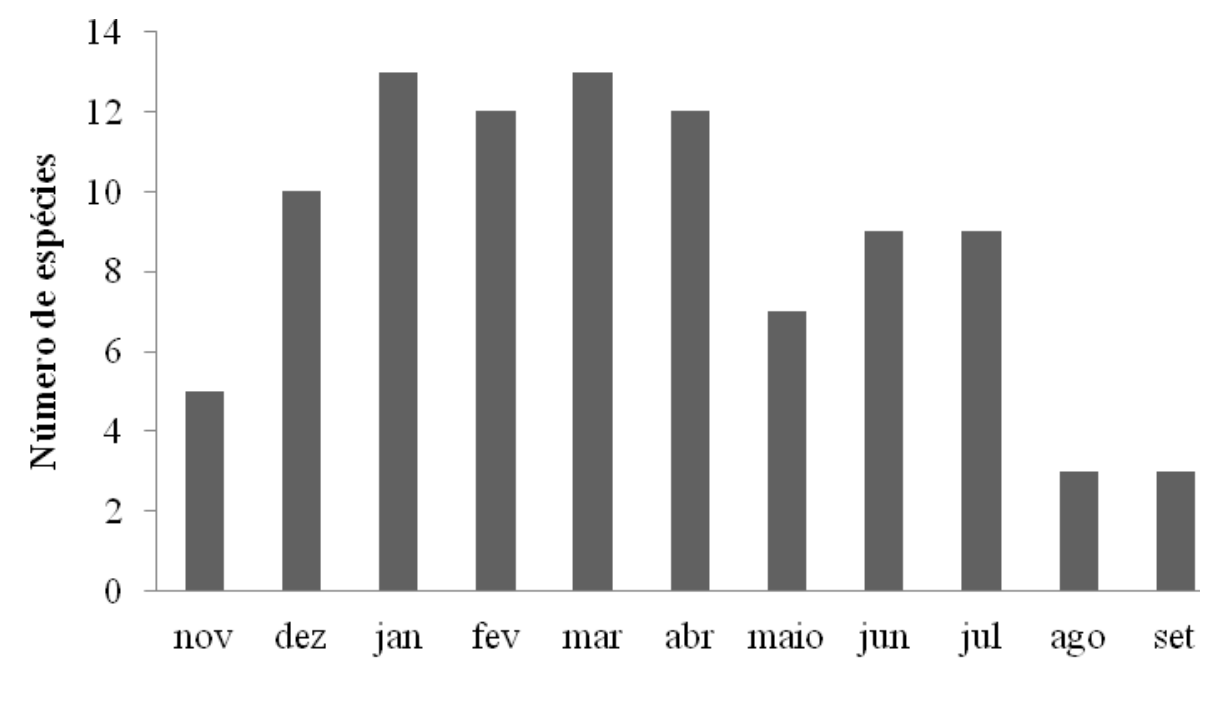

Meses de observação

A pesquisa de Morellato e Leitão-Filho (1992), na Serra do Japi, o estudo de Marchioretto (2007), no município de Palmares do Sul, RS e o estudo de Vinholes (2010), no município de Criciúma, SC, apresentaram disponibilidade de frutos durante todo o ano e pico de frutificação entre os meses de setembro e outubro, novembro e abril e maio, respectivamente. Em relação ao presente estudo, não houve variação na época de disponibilidade de frutos e sim no período de pico de frutificação.

Alguns fatores bióticos e abióticos podem influenciar no comportamento fenológico das comunidades vegetais, tendo como resultado uma grande dificuldade na definição de um padrão fenológico para comunidades tropicais, já que estas variações podem ocorrer até mesmo entre indivíduos da mesma espécie (VINHOLES, 2010). A comparação deste estudo com trabalhos realizados anteriormente confirma a variação existente no comportamento fenológico. 
A duração da frutificação variou de um a 11 meses, sendo que duas espécies apresentaram longos períodos de frutificação: Posoqueria latifolia que apresentou frutos maduros durante os 11 meses de estudo e Esenbeckia grandiflora que frutificou durante dez meses. Cerca de 67\% das espécies amostradas em frutos tiverem curto período de frutificação, variando de um a quatro meses (Tabela 1). Wessler (2008) encontrou padrão de duração semelhante, onde apenas $4 \%$ das espécies apresentaram longos períodos de frutificação, variando de sete a 11 meses. As duas espécies, Posoqueria latifolia e Esenbeckia grandiflora podem ser consideradas espécies-chave para a comunidade de aves na área do estudo, disponibilizando alimento constantemente durante quase o ano inteiro e, desta maneira, assegurando a manutenção das espécies de aves que se alimentam dos seus frutos.

Entre as espécies estudadas, 11 apresentaram hábito arbóreo e sete hábito arbustivo. As famílias mais representativas entre as árvores foram Myrtaceae, com três espécies (Marlierea eugeniopsoides, Myrcia palustris e Myrcia cf. pulchra) e Rubiaceae com duas espécies (Faramea montevidensis e Posoqueria latifolia). Nos arbustos, a família mais representativa foi a Melastomataceae, com duas espécies (Miconia cinerascens e Ossaea brachystachia).

O pico de frutificação das árvores ocorreu entre os meses de dezembro a julho, com cinco a sete espécies apresentando frutos maduros durante este período. $\mathrm{O}$ menor número de espécies registradas com frutos maduros ocorreu nos meses de agosto, setembro e novembro com três espécies em cada mês. Entre os arbustos, o pico de frutificação coincidiu parcialmente com o período de frutificação das árvores, ocorrendo nos meses de janeiro a abril, com quatro a seis espécies frutificando durante estes meses. O menor número de espécies com frutos maduros foi registrado entre os meses de maio a novembro, sendo que em agosto e setembro não foram observadas espécies arbustivas em frutificação (Figura 5).

Figura 5. Número de espécies com frutos maduros em relação ao hábito de crescimento os meses de estudo, no município de São João do Sul, SC. 


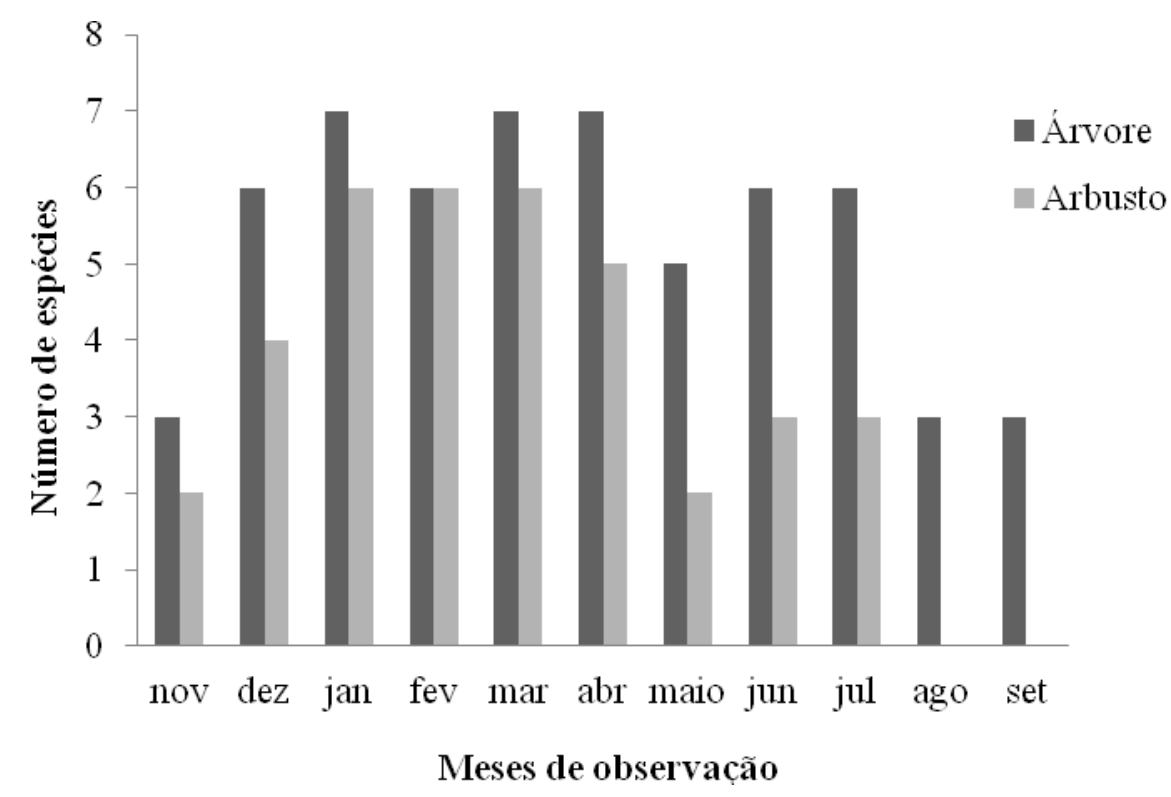

Os dados obtidos no presente estudo corroboram os resultados levantados por Zoucas (2002) que, com informações descritas na Flora Ilustrada Catarinense sobre a Floresta Ombrófila Densa no Sul de Santa Catarina, registrou o verão como a estação com maior número médio de espécies com frutos, seguida pelo outono e primavera, e o menor número de espécies frutificando foi observado no inverno. Entretanto, o baixo número de espécies arbustivos encontrado na área do estudo não permite generalizar estes resultados para a região do extremo sul catarinense.

\subsection{Estratégia de dispersão de diásporos}

Entre as 18 espécies registradas durante o período de estudo, 17 apresentaram estratégia de dispersão zoocórica, e apenas a espécie Esenbeckia grandiflora apresentou estratégia de dispersão autocórica (Tabela 1).

No fragmento estudado, as espécies com dispersão zoocórica apresentaram-se em maior quantidade na comunidade, corroborando diversos estudos que evidenciam que cerca de 60 a $90 \%$ das espécies vegetais de florestas tropicais apresentam estratégia de dispersão zoocórica (MORELLATO; LEITÃO-FILHO, 1992).

Costa et al. (2004), estudando uma área de Cerrado inserida no domínio semiárido no Ceará, encontrou uma predominância de zoocoria $(49,5 \%)$, seguida de autocoria $(28,1 \%)$ e anemocoria $(22,4 \%)$. Os autores ressaltaram ainda que, considerando apenas o componente arbustivo-arbóreo, a zoocoria foi predominante em 
71,6\% das espécies. Locatelli e Machado (2004), estudando uma área de brejo de altitude em Pernambuco, encontraram uma maior frequência de zoocoria (66\%), sendo esta síndrome mais representativa tanto na estação chuvosa quanto na seca. Andreis (2005) encontrou a zoocoria como estratégia de dispersão predominante em três fases sucessionais de uma Floresta Estacional Semidecidual no município de Santa Tereza, RS, seguida da anemocoria e a autocoria. Morellato e Leitão-Filho (1992) encontraram o mesmo padrão de estratégias de dispersão em duas formações florestais da Serra do Japi, SP. Esta proporção entre as estratégias de dispersão parece aumentar no estrato superior e a medida que as florestas tornam-se mais úmidas e menos sujeitas a estacionalidade climática (MORELLATO, 1991).

\section{CONCLUSÃO}

No presente estudo foram observadas 18 espécies vegetais em frutificação, sendo 11 com hábito de crescimento arbóreo e sete arbustivo, sendo que o número de espécies é considerado baixo em comparação com outros estudos realizados em outras regiões.

As famílias Melastomataceae, Myrtaceae e Rubiaceae foram as mais representativas, corroborando outros estudos realizados na Mata Atlândica, que consideram as espécies destas famílias de grande importância ecológica.

O fragmento ofereceu recursos alimentares durante todo o período da pesquisa e a maioria das espécies (17) apresentou frutos adaptados para dispersão zoocórica, com plantas exibindo frutos de cores vistosas e polpas suculentas, favorecendo a permanência de dispersores em todo o fragmento e seu entorno.

A maior quantidade de frutos disponíveis para a fauna foi na estação quente, entre os meses de janeiro e março e a estação fria apresentou uma redução significativa, principalmente das espécies arbustivas, sendo que nos meses de agosto e setembro não foram registradas espécies deste hábito com frutos. Entretanto, o baixo número de espécies arbustivos encontrado na área do estudo não permite generalizar estes resultados.

Os resultados evidenciam a necessidade da realização de mais estudos sobre a fenologia e estratégias de dispersão de diásporos com inclusão de diferentes hábitos em 
fragmentos urbanos, visto que foi encontrado um número muito baixo de espécies arbóreas e arbustivas com frutos.

\section{REFERÊNCIAS}

ALENCAR, J. C.; ALMEIDA, R. A.; FERNANDES, N. P. Fenologia de espécies florestais em floresta tropical úmida de terra firme na Amazônia Central. Acta Amazonica, v. 9, n. 1, p. 163-198, 1979.

AMESC (ASSOCIAÇÃO DOS MUNICÍPIOS DO EXTREMO SUL DE SANTA CATARINA). Dados do município. Araranguá. Disponível em:

<http://www.amesc.com.br/municipios/index.php>. Acesso em: 28 out. 2010.

ANDREIS, C. et al. Estudo fenológico em três fases sucessionais de uma floresta estacional decidual no município de Santa Tereza, RS, Brasil. Revista Árvore, Viçosa, v. 29, n. 1, p. 55-63, 2005.

APG III (The Angiosperm Phylogeny Group). An update of the Agiosperm Phylogeny Group classification for the ordens and families of flowering plants: APG III. Botanical Journal of the Linnean Society, v. 161, p. 105-121, 2009.

ARAÚJO, V.C. Fenologia de essências florestais amazônicas. Boletim do INPA. Série Pesquisas Florestais, v. 4, p.1-25, abr., 1970.

ATHAYDE, E. A. et al. Fenologia de espécies arbóreas em uma floresta ribeirinha em Santa Maria, sul do Brasil. Revista Brasileira de Biociências, Porto Alegre, v. 7, n. 1, p. 43-51, 2009.

BACKES, P; IRGANG, B. Árvores do Sul: Guia de Identificação \& Interesse Ecológico. As Principais Espécies Nativas Sul-Brasileiras. Porto Alegre: CD Vaz e Ricardo Correa, 2002. 325p.

BARROSO, G. M.; MORIN, M. P.; PEIXOTO, A. L.; ICHASO, C. L. F. Frutos e sementes: morfologia aplicada à sistemática de dicotiledôneas. Viçosa: Editora UFV, 1999. 305p.

BRAGA, H. J.; GHELLRE, R. Proposta de diferenciação climática para o Estado de Santa

Catarina. In: CONGRESSO BRASILEIRO DE AGROMETEOROLOGIA, 11, 1999, Florianópolis. Anais... Florianópolis: SBA, 1999. CD-Rom.

CAMACHO, M.; OROZCO, L. Patrones fenológicos de doce especies arbóreas del bosque montano de la Cordillera de Talamanca, Costa Rica. Revista de Biologia Tropicale, v. 46, n. 3, p. 533-542, 1998.

CARMO, M. R. B.; MORELATTO, L. P. C. Fenologia de árvores e arbustos das matas ciliares da bacia do rio Tibagi, estado do Paraná, Brasil. In: RODRIGUES, R. R.; LEITÃO-FILHO, H. (Ed.). Matas ciliares: conservação e recuperação. São Paulo: EDUSP. p. 125-141, 2000. 
COLONETTI, S. Florística e estrutura fitossociológica em Floresta Ombrófila Densa Submontana na barragem do rio São Bento, Siderópolis, Estado de Santa Catarina. Acta Scientiarum, Biological Sciences, Maringá, v. 31, n. 4, p. 397-405, 2011.

COSTA, I. R., ARAÚJO, F. S.; LIMA-VERDE, L.W. Flora e aspectos auto-ecológicos de um encrave de Cerrado na Chapada do Araripe, Nordeste do Brasil. Acta Botanica Brasílica v. 18, n. 4, p. 759-770, 2004.

EPAGRI/CIRAM. Zoneamento Agrológico e Socioeconômico do Estado de Santa Catarina. EPAGRI, 2001, CD-ROM.

FENNER, M. The phenology of growth and reproduction in plants. Perspectives in Plant Ecology, Evolution and Systematic v. 1, p. 78-91, 1998.

FIGUEIREDO, E. de. Fenologia reprodutiva de espécies arbóreas no campus da Universidade Federal Rural do Rio de Janeiro. 2007. Monografia (Trabalho de Conclusão de Curso em Engenharia Florestal) - Universidade Federal Rural do Rio de Janeiro, Rio de Janeiro, 2007.

FIGUEIREDO, P. S. de. Fenologia e estratégias reprodutivas das espécies arbóreas em uma área marginal de cerrado, na transição para o semi-árido no nordeste do Maranhão, Brasil. Revista Trópica Ciências Agrárias e Biológicas, v. 2, n. 2, p. 8, 2008.

FIGLIOOLIA, M. B. Maturação de sementes de Inga uruguensis Hook et Arn. Associada à fenologia reprodutiva e a dispersão de sementes em floresta ripária do rio Mogi Guaçu - município de Mogi Guaçu, São Paulo. 1993. Dissertação (Mestrado em Engenharia Florestal) - Escola Superior de Agricultura Luiz de Queiroz, Universidade de São Paulo, São Paulo, 1993.

FOURNIER, L. A. Un método cuantitativo para la medición de características fenológicas en árboles. Turrialba, Turrialba, v. 24, n. 4, p. 422-423, 1974.

FREITAS, J.L. Fenologia de espécies arbóreas tropicais na Ilha do Pará- Pará no estuário do rio Amazonas. 1996. Dissertação (Mestrado em Ciências Agrárias). Faculdade de Ciências Agrárias do Pará, Belém, 1996.

GONDIM, M. J.C. Dispersão de sementes de Trichilia spp (Meliaceae) por aves em um fragmento de mata mesófila semidecídua, Rio Claro, SP, Brasil. Ararajuba v.10, p. 01$112,2001$.

GOOGLE EARTH. Disponível em: <http://www.google.com/intl/ptPT/earth/index.html>. Acesso em: 30 out. 2011.

GRANDISOLI, E. A. C. Biologia reprodutiva e estrutura da população de Psychotria suterella Muell. Arg. (Rubiaceae) em um fragmento de mata secundária em São Paulo (SP). 1997. Dissertação (Mestrado), Universidade de São Paulo, São Paulo, 1997.

GRIFFITH, J. J.; DIAS, L. E.; JUCKSCH, I. Recuperação de áreas degradadas usando vegetação nativa. Saneamento Ambiental, n. 37, p. 28-37, 1996.

HOWE, H. F.; SMALLWOOD, J. Ecology of seed dispersal. Annual Review of Ecology and Systematics v. 13, p. 201-228, 1982. 
LIMA, H. A. Heterostilia em Psychotria leiocarpa Cham. \& Schl. (Rubiaceae). Boletim do Museu Nacional, v. 76, p. 1-16, 1988.

LOCATELLI, E.; MACHADO, I. C. Fenologia das espécies arbóreas de uma mata serrana (brejos de altitude) em Pernambuco, Brasil. In: PORTO, K. C.; CABRAL, J. J. P.; TABARELLI, M. (Orgs). Brejos de altitude em Pernambuco e Paraíba: história natural, ecologia e conservação. Brasília: Ministério do Meio Ambiente, Série biodiversidade, 9, p. 255-276, 2004.

LONGMAN, K.A.; JENIK, J. Tropical forest and its environment. Singapore: Longman Singapore, 1987.

LORENZI, H. Árvores Brasileiras: Manual de identificação e cultivo de plantas arbóreas nativas do Brasil. Plantarum, Nova Odessa. v. 1, p. 450, 1992.

LORENZI, H. Árvores Brasileiras: Manual de identificação e cultivo de plantas arbóreas nativas do Brasil. 2. ed. Ed. Plantarum, Nova Odessa. v. 2. 480 p, 1998.

MABBERLEY, D. J. The Plant-Book: a Portable Dictionary of the Vascular Plants. Reino Unido: Cambridge, University Press, 1997. 806p.

MANTOVANI, M. et al. Fenologia reprodutiva de espécies arbóreas em uma formação secundária da floresta Atlântica. Revista Árvore, v. 27, n. 4, p. 451-458, 2003.

MAPA INTERATIVO DE SANTA CATARINA. Disponível em: http://www.mapainterativo.ciasc.gov.br/sc.phtml\#. Acesso em: 06 de maio de 2014.

MARTINS, R. Florística, estrutura fitossociológica e interações interespecíficas de um remanescente de Floresta Ombrófila Densa como subsídios para a recuperação de áreas degradadas pela mineração de carvão, Siderópolis, SC. Florianópolis, 2005. Dissertação (Mestrado em Biologia Vegetal) - Universidade Federal de Santa Catarina, Santa Catarina, 2005.

MARCHIORETTO, M. S.; MAUHS, J.; BUDKE, J. C. Fenologia de espécies arbóreas zoocóricas em um a floresta psamófila no sul do Brasil. Acta Botanica Brasílica, v. 21, n. 1, p. 193-201, 2007.

MARQUES, M. C. M.; OLIVEIRA, P. E. A. M. Fenologia de espécies do dossel e do sub-bosque de duas florestas de restinga da Ilha do Mel, sul do Brasil. Revista Brasileira de Botânica, v. 27, n. 4, p. 713-723, 2004.

MIKICH, S. B.; SILVA, S. M. Composição florística e fenologia de espécies zoocóricas de remanescentes de floresta estacional semidecidual no centro-oeste do Paraná, Brasil.

Acta Botanica Brasílica, v. 15, n. 1, p. 89-113, 2001.

MORELATTO, L. P. C.; RODRIGUES, R. R.; LEITÃO-FILHO, H. F.; JOLY, C. A. Estudo fenológico comparativo de espécies arbóreas de floresta de altitude e floresta mesófila semidecídua na Serra do Japi, Jundiaí, SP. Revista Brasileira de Botânica, v. 12, n. 3, p. 85-98, 1989. 
MORELATTO, L. P. C.; LEITÃO-FILHO, H. F.. Estratégias fenológicas de espécies arbóreas em floresta mesófila na Serra do Japi, Jundiaí, SP. Revista Brasileira de Biologia, v. 50, p. 163-173, 1990.

MORELATTO, L. P. C. Fenologia de árvores, arbustos e lianas em uma floresta semidecídua no sudeste do Brasil. 1991. Tese (Doutorado em Ecologia) Universidade de Campinas, São Paulo, 1991.

MORELATTO, L. P. C.; LEITÃO-FILHO, H. F. Padrões de frutificação e dispersão da Serra do Japi. In: MORELLATO, L. P. C. (Org). História natural da serra do Japi: ecologia e preservação de uma área florestal no Sudeste do Brasil. Campinas: Unicamp, p. 112-140, 1992.

MORELATTO, L. P. C. Ecologia e preservação de uma floresta tropical urbana: reserva de Santa Genebra. São Paulo: Unicamp, 1995.

MORELATTO, L.P.C.; LEITÃO-FILHO, H.F. . Reprodutive phenology of climbers in a Southeasthern Brasilian Forest. Biotropica, v. 28, p. 180-191, 1996.

MORELATTO, L.P.C. et al. Phenology of Atlantic Rain Forest trees: a comparative study. Biotropica, v. 32, p. 811-823, 2000.

NEGRELLE, R. R. B. Composição florística e estrutura vertical de um trecho de Floresta Ombrófila Densa de Planície Quaternaria. Hoehnea, v. 33, n. 3, p. 261-289, 2006.

PACHECO, S.; GRAU, R. Phenology of an understory shrub and bird-dispersal in relation to tree-fall gaps in a subtropical montane forest of Northwest Argentina. Ecologia Austral, v. 7, p. 35-41, 1997.

PALIOTO, G. et al. Fenologia de espécies arbóreas no campus da Universidade Estadual de Maringá. Revista Brasileira de Biociências, Porto Alegre, v. 63, n. 2, p. 329-339, 2007.

PIRES, M.J. Phenology of tropical trees from Jari, Lower Amazon, Brazil. 1991. 322f. Tese (Doutorado) - University of London, London, 1991.

PIZO, M. A. Frugivoria e dispersão de sementes por aves. In: V Congresso Brasileiro de Ornitologia, Anais.., UNICAMP, Campinas, 1996.

PEREIRA, T. S. et al. Fenologia de espécies arbóreas em Floresta Atlântica da reserva Biológica de Poço das Antas, Rio de Janeiro, Brasil. Iheringia, Série Botânica, Porto Alegre, v. 63, p. 329-339, 2008.

POTT, A.; POTT, V.J. Plantas do Pantanal. Brasília: EMBRAPA, 1994. 480p.

PMSJS. PREFEITURA MUNICIPAL DE SÃO JOÃO DO SUL. Características do município. Disponível em: 〈http://www.saojoaodosul.sc.gov.br/home/index.php>. Acesso em: 19 ago. 2010.

REYS, P.; GALETTI, M.; MORELLATO, L. P. C.; SABINO, J. Fenologia reprodutiva e disponibilidade de frutos de espécies arbóreas em mata ciliar no Rio Formoso, Mato Grosso do Sul. Biota Neotropica, São Paulo, v. 5, n. 2, p. 1-10, 2005. 
ROBBRECHT, E. Tropical woody Rubiaceae: characteristic features and progression contributions to a new subfamilia classification. Opera Botanica, Belgica, v. 1, p. 1$271,1988$.

ROMAGNOLO, M. B. A família Myrtaceae na estação ecológica do Caiuá, Diamante do Norte, PR. 2009. Tese (Doutorado) - Departamento de Biologia, Universidade Estadual de Maringá, Maringá, 2009.

ROMERO, R; MARTINS, A. B.. Melastomataceae no parque nacional da Serra da Canastra, Minas Gerais, Brasil. Revista Brasileira de Botânica, São Paulo, n. 1, p. 1924, 2002.

ROTH, I. Stratification of a tropical forest as seen in dispersal types. Dordrecht: Dr W. Junk Publishers, 1987.

SILVA, R. T. Florística e Estrutura da sinúsia arbórea de um fragmento urbano de Floresta Ombrófila Densa no município de Criciúma, Santa Catarina. Criciúma, 2006. Dissertação (Mestrado em Ciências Ambientais) - Universidade do Extremo Sul Catarinense, Santa Catarina, 2006.

TALORA, D. C.; MORELATTO, L. P. C. Fenologia de espécies arbóreas em floresta de planície litorânea do sudeste do Brasil. Revista Brasileira de Botânica, v. 23, n. 1, p. 13-26, 2000.

UNIVERSIDADE DO ESTADO DE SANTA CATARINA. Disponível em: http://www.udesc.br/?id=1069. Acesso em: 06 de maio de 2014.

VAN SCHAIK, C. P.; TERBORGH, J. W.; WRIGTH, S. J. The phenology of tropical forests: adaptative significance and consequences for primary consumers. Annual Review of Ecology and Systematics, v. 24, p. 353-377, 1993.

VAN DER PIJL. Principles of dispersal in higher plants. 1982, 162p.

VASCONCELOS, S. F. de. Fenologia e síndrome de dispersão de espécies arbustivas e arbóreas em uma área de Carrasco no Planalto de Ibiapaba, Ceará. 61f. Dissertação (Mestrado em Biologia Vegetal) - Universidade Federal de Pernambuco, Pernambuco, 2006.

VINHOLES, A. R. Avifauna e fenologia da frutificação em fragmento urbano de floresta ombrófila densa submontana, Criciúma, Santa Catarina. 2010. Dissertação (Mestrado em Ciências Ambientais) - Universidade do Extremo Sul Catarinense, Santa Catarina, 2010.

WESSLER, B. Fenologia da frutificação e estratégias de dispersão de diásporos em fragmentos de Mata Atlântica, no município de Içara, Santa Catarina. 2008. Monografia (Trabalho de Conclusão de Curso em Ciências Biológicas) - Universidade do Extremo Sul Catarinense, Santa Catarina, 2008.

ZOUCAS, B. C. Subsídios para restauração de áreas degradadas: banco de dados e análise das espécies vegetais de ocorrência no sul de Santa Catarina. $2002132 \mathrm{f}$. Dissertação (Mestrado em Biologia Vegetal) - Universidade Federal de Santa Catarina, Florianópolis, 2002. 
Revista Tecnologia e Ambiente, v. 21, n.1, 2015, Criciúma, Santa Catarina. ISSN: 1413-8131 (versão impressa) ISSN: 2358-9426 (versão eletrônica) 